\title{
Consumer satisfaction of patients attending psychiatry of learning disabilities clinics
}

\author{
Karen Bretherton and Shaun Gravestock
}

\begin{abstract}
A consumer satisfaction survey of patients with learning disabilities and mental health needs aftending outpatient peychiatry clinics was pertormed using a questionnaire administered by their carer. Sixty completed questionnalres were returned and the results were analysed to determine whether demographic or service varlables were correlated with the degree of satisfaction. Younger patients living independentty or with their family and those who were not prescribed peychotrople medication were more sotistied. The service varlables associated with increased sattistaction were comfortable walting areas, punctuallity and good communication with the doctors.
\end{abstract}

Following the hospital closure programmes in the South East Thames region there are now a large number of patients with both learning disabilities (LD) and mental health needs (MHN) living in the community. Their psychiatric treatment occurs more frequently in out-patient settings, which improves the use of clinicians' time; also, such services may be integrated with parallel generic psychiatry resources.

People with LD should expect to have access to quality services and thus it is useful to evaluate their perception of the service provided as part of quality assurance. Recent White Papers have favoured actively seeking 'consumer' opinion as a means of improving the quality of services as consumers are no longer considered to be passive users (Gravestock, 1994). While others have explored the views of carers using LD services (Hall \& Pieri, 1992), there has been no recent research on consumer satisfaction of adults with LD and MHN attending local psychiatric outpatient departments. This is in spite of the increasing recognition of their mental health and social care needs by specialist community psychiatry services (Bouras \& Drummond, 1992).

The difficulties in interviewing people with $\mathrm{LD}$ include acquiescence, poor response to open questions, suggestibility and communication problems (Atkinson, 1988). The challenge remains for service researchers to involve these patients effectively so that they can express their viewpoint accurately.

\section{The study}

The aim of the study was to relate measured dimensions of consumer satisfaction with patient and service variables. The study questionnaire was devised to incorporate patient demographic and clinical data, coded to maintain anonymity. It included seven yes/no items and nine semantic differential questions. After each clinic appointment patients were asked if they would complete a questionnaire with their carer administering questions and recording their responses.

The study included all patients seen in three adult psychiatry of LD clinics serving the innerLondon boroughs of Lewisham and Southwark who agreed to participate during the five-month study period. The data from the patients who had severe LD were excluded from the statistical analysis because their poor verbal comprehension and expressive skills made it unlikely that the responses recorded were a reliable and valid representation of their own views, but rather were to be those of their carers. No patients with a profound LD were seen in the clinic.

The responses to the yes/no questions were scored on a $0-2$ scale with $0=$ no reply, $1=$ dissatisfied and $2=$ satisfied. The response to the semantic differential questions were scored on a $0-4$ scale with $0=$ no reply, $1=$ very dissatisfied, $2=$ dissatisfied, $3=$ satisfied and $4=$ very satisfied. Results were coded and scored according to the level of satisfaction expressed for each item.

\section{Findings}

Demographic and clinical data

Sixty-five questionnaires were returned (response rate $73.0 \%$ ). Data from five patients were excluded as they had a severe learning disability. giving a response rate of $71.4 \%(27$ (45\%) male, $33(55 \%)$ female) for further analysis. The age range of respondents was 18-71 years with a mean of 39.8 (s.d.=14.0). Their level of $L D$ was as follows: borderline [IQ 70-80] 13 (21.7\%); mild [IQ $50-70$ ] 27 (45\%); moderate [IQ 35-50] 20 (33.3\%). The main reason for attendance was for 
Table 1. Service delivery variables

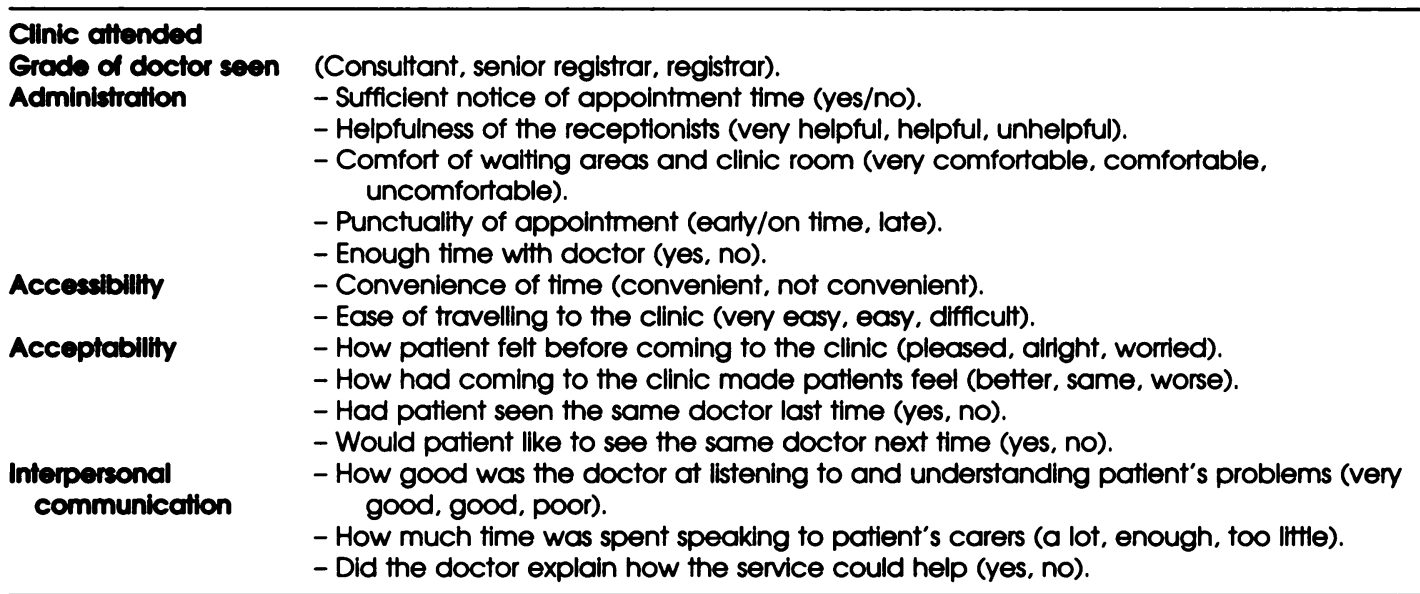

treatment of psychiatric illness in 41 (68.3\%) cases and a behavioural problem in 19 (31.7\%). Medication was being prescribed in 45 patients (73.3\%). Verbal communication abilities were considered to be adequate for interview in 47 (78.3\%) patients and problems were encountered at interview with $13(21.7 \%)$.

The carer present with 40 patients $(66.7 \%)$ was a support worker while 20 patients (33.3\%) attended with a family member or professional. Clinic 1 was attended by $15(25 \%)$ patients, clinic 2 by $22(36.7 \%)$ patients and clinic 3 by 23 (38.3\%) patients. The consultants saw $34(56.7 \%)$ patients, the senior registrar saw $12(20 \%)$ patients and the registrar saw 14 (23.3\%).

\section{Satisfaction scores}

The mean satisfaction score was 35.3 (range 2742; s.d. 3.2). The satisfaction score of 35 was used to divide the sample into two groups, i.e. higher satisfaction was $>35$ and lower satisfaction was $<35$. These two patient groups were compared using chi-squared tests (with Yates correction if indicated) to check for statistical differences in demographic, clinical, as well as service delivery variables.

Concerning patient demographic and clinical variables, the only statistically significant findings were: patients expressed greater satisfaction with their clinic attendance if living at home or independently compared with living in supported residence $\left(\chi^{2}=4.53\right.$, d.f. $\left.=1, P<0.05\right)$; attended clinics with a family member rather than a support worker $\left(\chi^{2}=4.53\right.$, d.f. $\left.=1, P<0.05\right)$; and if they were not receiving psychotropic medication $\left(\chi^{2}=5.14\right.$, d.f. $\left.=1, P<0.05\right)$.

The service delivery variables are listed in Table 1.
The significant results were as follows: patients expressed greater satisfaction if they found the waiting areas very comfortable $\left(\chi^{2}=9.52\right.$, d.f. $=2$, $P<0.01)$, were seen early or on time $\left(\chi^{2}=6.29\right.$, d.f. $=1, P<0.02$ ), felt better following the appointment $\left(\chi^{2}=10.67\right.$, d.f. $\left.=2, P<0.01\right)$, felt that the doctor listened and understood their problem $\left(\chi^{2}=21.03\right.$, d.f. $\left.=2, P<0.001\right)$, felt that the doctor had spent a lot of time speaking to their carers $\left(\chi^{2}=11.03\right.$, d.f. $\left.=2, P<0.01\right)$ and if the doctor had explained how the services might be able to help $\left(\chi^{2}=9.27\right.$, d.f. $\left.=1, P<0.01\right)$.

\section{Comments}

The survey population was broadly representative of the patients attending local psychiatry of $\mathrm{LD}$ clinics in that the majority lived in supported community residences and attended for assessment and treatment of psychiatric illness. However, although patients with all levels of $L D$ attend the clinics, data from those with severe disability had to be excluded from this study as discussed above.

The questionnaire used was agreed by colleagues to have face validity but due to changing service and patient variables it proved practically impossible to assess the test/re-test reliability. Therefore the results of this empirical survey should be considered suggestive rather than definitive. Whether patients had borderline, mild or moderate LD or different levels of communication ability did not appear to influence their capacity to express high or low satisfaction and there was little evidence of acquiescence in their responses. Suggestibility and social desirability effects cannot be excluded, given the limited responses of many patients to the open questions (Atkinson, 1988). 
The analysis of patient variables suggested that the younger patient group was more satisfied with the clinics. This may be because they were less likely to have spent several years living in hospital and were therefore more accustomed to attending clinics and GP surgeries for their health care.

Patients who lived independently or with their family, and attended with a family member expressed more satisfaction. Reasons for this difference may include a genuine appreciation of the community-based services which aim to maintain people in community settings or conversely the patients in supported residences are enabled by their support workers to express more general and specific dissatisfaction. Thus, future similar studies also comparing the views of patients with those of their carers would be useful.

Patients who were not receiving medication generally scored greater levels of satisfaction. Those receiving medication may be less compliant or have less insight into the reasons for their medication and their psychiatric morbidity could be affecting their perception of the service.

It was reassuring to find that $95 \%$ of clinic attenders found the clinic times convenient and 98.3\% were given sufficient notice of the appointment. Of the service delivery variables significantly associated with increased satisfaction, the finding on how good the doctor was at listening and understanding problems was particularly significant. This is a strong indication that good doctor-patient communication is vital to consumer satisfaction in psychiatry of LD clinics as in other clinics. Several of these findings support those of similar studies (Sheikh \& Meakin, 1990) and as expected, this study showed that those who scored higher levels of satisfaction generally felt better after their attendance.

The survey proved useful in assessing the patient and service variables associated with the consumer satisfaction of adults with mild and moderate LD. We hope that similar studies could research the satisfaction of other groups of people with $L D$ such as those with epilepsy and physical disabilities. However, different methods will be required in order to assess adequately the views of children and adults with more severe $L D$.

\section{Acknowledgements}

We are grateful to Dr Nick Bouras for helpful comments and to Mrs Beryl Clark for invaluable administrative assistance.

\section{References}

ATKINSON, D. (1988) Research interviews with people with mental handicaps. Mental Handicap Research, 1, 75-90.

BOURAS, N. \& DRUMMOND, K. (1992) Behaviour and psychiatric disorders of people with mental handicaps living in the community. Joumal of Intellectual Disability Research, 36, 349-357.

GRAVESTOCK, S. (1994) Quality assurance for adults with mental retardation and mental health needs. In Mental Health in Mental Retardation (ed. N. Bouras), pp. 319 327. Cambridge: Cambridge Untversity Press.

HALL, D. J. \& PIERI, L. F. (1992) Providing a community mental handicap service. Psychiatric Bulletin, 16, 20-21.

SHEIK, A. J. \& MEAKIN, C. (1990) Consumer satisfaction with a psychiatric out-patient clinic. Psychiatric Bulletin. 14. 271-274.

* Karen Bretherton, formerly Registrar in Psychiatry of Learning Disabilities, Division of Psychiatry, UMDS and Guy's Hospital London, currently Senior Registrar in Psychiatry of Learning Disabilities, Northgate Hospital, Morpeth, Northumberland NE61 3BP; and Shaun Gravestock, formerly Lecturer/Senior Registrar in Psychiatry of Learning Disabilities, UMDS and Guy's Hospital London, currently Consultant in Psychiatry of Learning Disabilities, Northgate Hospital, Morpeth, Northumberland NE61 3BP

*Correspondence 